\title{
Granular Sorbents for Passive Environment Protection System during Severe Accidents with Total Loss of Power Supply at NPPs
}

\author{
Alexey A. Bessonov, Sergey A. Kulyukhin, Natalya A. Konovalova, Lubov V. Mizina, \\ Igor A. Rumer \\ Frumkin's Institute of Physical Chemistry and Electrochemistry, Russian Academy of Sciences, Moscow, Russia \\ Email: Bessonov ipc@mail.ru
}

Received November 2014

\begin{abstract}
Institute of Physical Chemistry and Electrochemistry, Russian Academy of Sciences has developed some novel sorbents designed for the filter units of the passive filtration system for radioactive discharge from the intercontainment space during heavy accidents with a complete loss of electricity supply at nuclear power plants. These are granulated sorbents based on large-pore silica gel containing nanometric particles of Ag or Ag-Ni compounds (trademark Fizkhimin). The sorbents allow to remove various radioactive iodine species (inorganic ones and methyl iodide) from a steam-gas phase with at least $10^{4}$ decontamination factor. The high sorption properties of Fizkhimin sorbent with Ag particles were confirmed during tests at a test facility of the TUV Sudwest company (Karlsruhe, Germany). This passive filtration system is installed at the $1^{\text {st }}$ and $2^{\text {nd }}$ units of the Kudankulam nuclear power plant (India) and it is unique in the world practice.
\end{abstract}

\section{Keywords}

Nuclear Power Plant, Sorbent, Radioactive Iodine

\section{Introduction}

The problem of reliable environmental protection measures in the event of severe nuclear power plant accidents appears to be an important factor restraining the development of nuclear energy. It is known that a hypothetic severe accident accompanied by a partial or complete destruction of the reactor's active zone, bring about the formation of large quantities of gaseous products. This leads to an abrupt increase in pressure inside the containment and there is a risk of its destroying. Besides, due to leakage through non-airtight sectors of the containment the radioactive steam-air mixture may penetrate to the other areas of plants, such as the intercontainment space, technical and service zones and than from these areas to the environment. For decreasing of the pressure inside the containment, the some nuclear power plants are equipped with pressure release system. The modern designs of new-generation nuclear power plants with two protective shells do not provide for pressure release systems [1]-[3]. It is planned that during hypothetical severe accidents all radioactive products will be 
localized inside containment. But calculations, which was made for LOCA accidents at PWR NPP, show that during accident during $122 \mathrm{~h}$, pressure under the containment can rise up to $0.7 \mathrm{MPa}$, with the steam/air ratio being 2.7 to 1 . This time is enough for penetration of the radioactive steam-air mixture from containment into the intercontainment area and then into the environment. To prevent radioactive contamination of the environment, modern designs are equipped with active venting filtering systems, which require regular electric power supply. However, in accordance with the general requirements for safety systems, alongside active ventilation systems for intercontainment space, nuclear power plants should include a passive ventilation system, which can be used during hypothetical severe accident with a complete loss of power supply.

\section{Results and Discussion}

Based on the fundamental studies on localization of volatile fission products the new passive environment protection system during severe accidents at new generation NPPs is suggested [4]-[6]. The main purpose of developed passive filtration system is creation of a rarefaction in an intercontainment space due to the organized removal of the radioactive steam-air mixture from an intercontainment space at full loss of all power sources. Steam-air mixture containing radioactive aerosols and flying fission products removal from an intercontainment space is passed through the special filtering module (Figure 1). Efficiency of cleaning of a radioactive steam-air mixture is determined by filtration and sorption properties of used filtering elements. The following engineering requirements to given filter under development were showed.

The flow rated speed of the filtered medium is not less than $400 \mathrm{~m}^{3} / \mathrm{h}(0.135 \mathrm{~kg} / \mathrm{s}$ by dry air $)$ at temperature $20^{\circ} \mathrm{C}$ and pressure $0.1 \mathrm{MPa}$. At the specified rated speed pressure difference on the filtering module should not exceed $20 \mathrm{~Pa}$ at $20^{\circ} \mathrm{C}$ and $0.1 \mathrm{MPa}$ (or $48 \mathrm{~Pa}$ at temperature $280^{\circ} \mathrm{C}$ ). The filtering module should provide filtration and sorption properties in a temperature range from $20^{\circ} \mathrm{C}$ to $300^{\circ} \mathrm{C}$. Under these conditions, efficiency of the decontamination of the steam-air environment with water vapor content up to about 30 vol.\% should be not less than $99.9 \%$ from molecular iodine $\left(\mathrm{I}_{2}\right)$ and not less than $99.0 \%$ from organic compounds of iodine $\left(\mathrm{CH}_{3} \mathrm{I}\right)$. At the same time during filtering module heating up to temperature $300^{\circ} \mathrm{C}$ the level of radioactive iodine desorption should not exceed $0.1 \%$ from a total quantity of the compounds located in the module.

Fundamental studies on localization of molecular and organic forms of radioactive iodine from a steam-air flow in operating conditions of passive filtering system allowed to select for this filtering module sorbents "Fizkhimin",TM , including nanometric particles of Ag or Ag-Ni compounds.

The granulated sorbent "Fizkhimin"TM represents silica impregnated by Ag or Ag-Ni and modified on technique of IPCE RAS (Figure 2 and Figure 3) [7] [8].

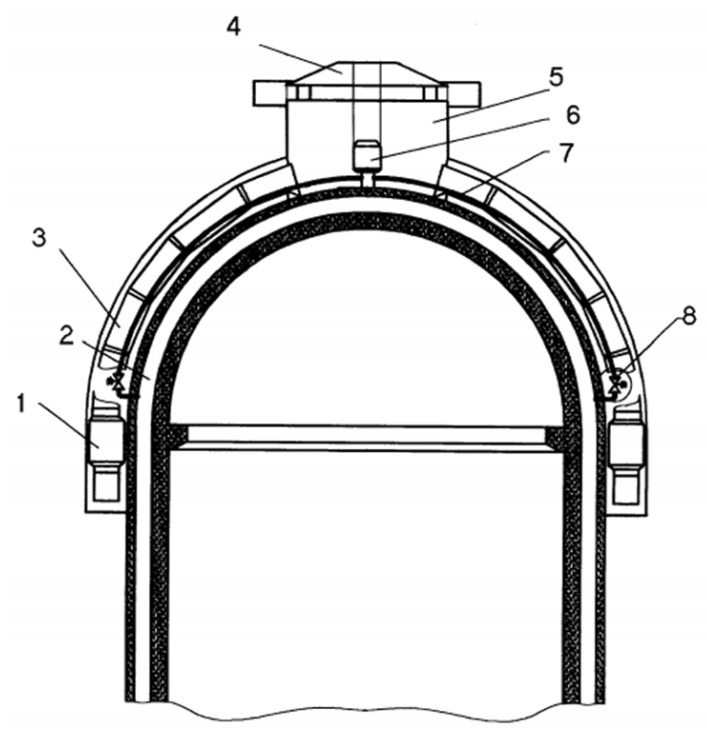

Figure 1. The layout of the passive filtering system for decontamination of intercontainment area (1-heat-exchanger of the passive heat-removal system, 2-intercontainment area, 3-pipe of the passive heat-removal system, 4-deflector, 5-collector of the passive heat-removal system, 6-filtering unit, 7-piping, 8-valve with pneumatic drive). 


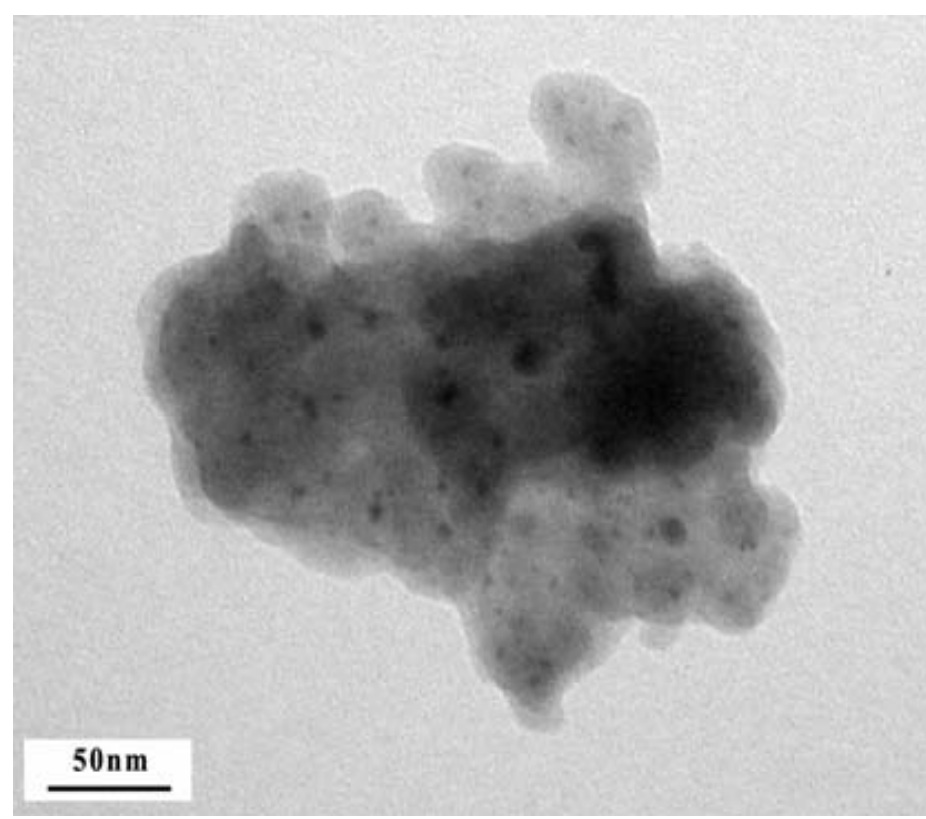

Figure 2. The sorbent "Fizkhimin"TM based on Ag nanometric compounds (Electronic microscope EM-301 “Philips”).

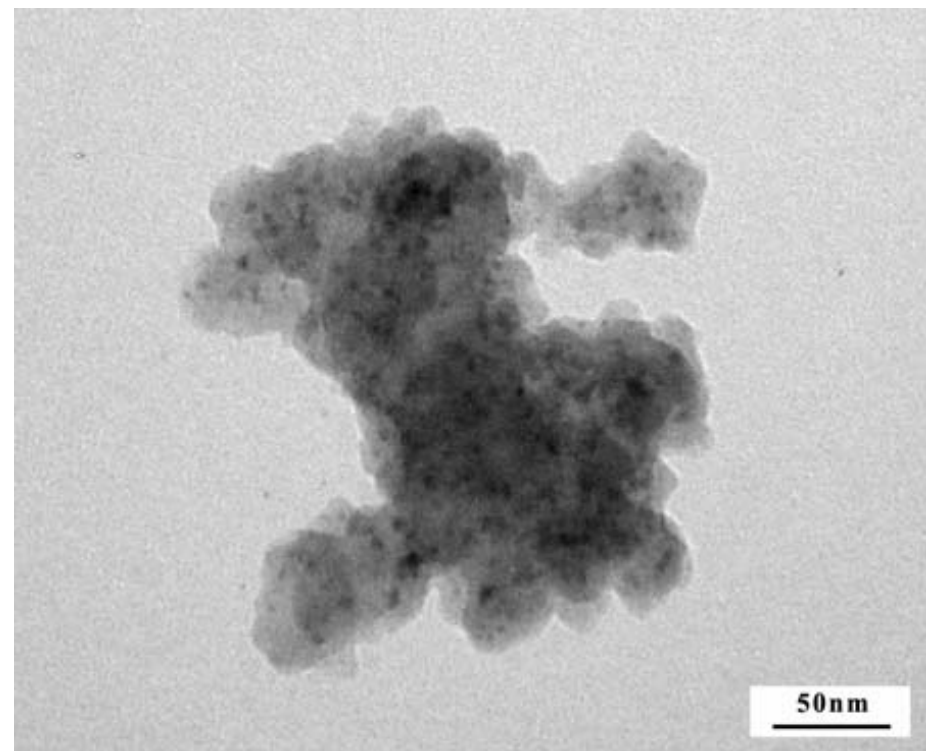

Figure 3. The sorbent "Fizkhimin",TM based on Ag-Ni nanometric compounds (Electronic microscope EM-301 "Philips”).

The sorbent is manufactured in several types and represents granules of dark color with the sizes of particles $0.5-6.0 \mathrm{~mm}$. The studies of sorbent properties have shown, that it is radiationally resistant at a doze $500 \mathrm{MRad}$ and does not initiate ignition of hydrogen. The basic physical and chemical characteristics of these sorbents are presented in Table 1. As shown from Table 1, the given sorbents have high sorptive efficiency in relation to molecular iodine and iodide methyl. At that it is necessary to note, that they do not lose the sorptive efficiency up to temperature $300^{\circ} \mathrm{C}$ and up to temperature $600^{\circ} \mathrm{C}$ from them does not occur the desorption of radioactive iodine in a gas phase (Table 2).

Taking into account novelty of development and an opportunity of the international application of passive filtering system (the Russian project of the NPP WWER-1000 in India), expert international tests of efficiency of 
sorbents "Fizkhimin",TM on absorption of volatile radioactive iodine compounds at the stand of "TUV Energie und System Technic” (TUV ET) (Karlsruhe, Germany) have been carried out. Testing passed on localization most difficult sorptive form of the radioactive iodine - methyl iodide. Test facility concluded the following basic parts: a thermostatically controlled by hot air two-section tight chamber; a steam generator; a condenser; a column with a tested sorbent; columns with a control sorbents; rotameters; container with water; balance; peristaltic pump; manometers; the compressor or preevacuation pump.

Experiments were carried out as follows. A columns with sorbent "Fizkhimin"TM and control sorbents, a steam generator installed in a two-section tight chamber. Their heating was carried out with the help of heated up air. Amount of water in a steam-air mixture created as follows. Strictly given amount of water submitted to a steam generator with help of peristaltic pump. Simultaneously the certain amount of air submitted to a steam generator. In a steam generator water evaporated, mixed up with air and moved into superheater of a steam-air mixture. During passing of a steam-air mixture through superheater there is occured a thermostating of a gas phase. The column containing sorbent "Fizkhimin" ${ }^{\text {TM }}$ preliminary heat up and blow a steam-air mixture of the certain content within $2 \mathrm{~h}$. Simultaneously the heating of a steam generator, columns with control sorbents, and also superheater of steam-air mixture carried out. After the ending of preliminary blowing and thermostating of facility a gaseous $\mathrm{CH}_{3}{ }^{131}$ I from special vessel began to include on a facility. The steam-air mixture mixed with $\mathrm{CH}_{3}{ }^{131} \mathrm{I}$ and than directed on a column with a tested sorbent within $30 \mathrm{~min}$. After the ending of including of $\mathrm{CH}_{3}{ }^{131} \mathrm{I}$ a thermostating steam-air mixture blowed through a column during 16 - $18 \mathrm{~h}$. After a column with a sorbent "Fizkhimin" ${ }^{\text {,TM }}$ the radioactive steam-air mixture goes on a column with control sorbents and than into a condenser. In a condenser there is occured the condensation of the basic amounts of water. After the ending of test a distribution of ${ }^{131} \mathrm{I}$ in a column with sorbent "Fizkhimin",TM and columns with control sorbents was investigated. On the basis of the data of the ${ }^{131}$ I distribution the decontamination factor DF of cleaning of a steam-air mixture from $\mathrm{CH}_{3}{ }^{131}$ I was calculated. Results of tests (Table 3) have shown, that sorbents have very high sorptive efficiency relative to most difficult localize form-to methyl iodide, at various experimental parameters.

Table 1. Main properties of the granular sorbent “Fizkhmin”,TM .

\begin{tabular}{|c|c|}
\hline Parameter & Value \\
\hline Colour & grey \\
\hline Form & granular \\
\hline Particle size, $\mathrm{mm}$ & $0.25 \div 6.0$ \\
\hline Metal concentration in the sorbent, wt.\% & $3 \div 10$ \\
\hline Heat capacity, $\mathrm{J} \cdot \mathrm{kg}^{-1} \cdot \mathrm{K}^{-1}$ & $\geq 795.5$ \\
\hline Heat conductivity, $\mathrm{W} \cdot \mathrm{m}^{-1} \cdot \mathrm{K}^{-1}$ & $\geq 1.4$ \\
\hline $\mathrm{P}, \mathrm{kg} / \mathrm{m}^{3}$ & $550 \pm 100$ \\
\hline Unconfined space, \% & $60 \div 80$ \\
\hline Specific surface, $\mathrm{m}^{2} / \mathrm{g}$ & $310 \pm 20$ \\
\hline Average pore radius, $\AA$ & $55 \pm 10$ \\
\hline Total pore volume, $\mathrm{cm}^{3} / \mathrm{g}$ & $1.4 \pm 0.2$ \\
\hline $\begin{array}{l}\text { Sorptive capacity, g per } 1 \mathrm{~kg} \text { of sorbent } \\
\qquad \mathrm{CH}_{3} \mathrm{I} \\
\mathrm{I}_{2}\end{array}$ & $\begin{array}{c}6 \div 25 \\
15 \div 60\end{array}$ \\
\hline $\begin{array}{l}\text { Sorptive efficiency }{ }^{*}, \% \\
\mathrm{CH}_{3}^{131} \mathrm{I} \\
{ }^{131} \mathrm{I}_{2}\end{array}$ & $\begin{array}{l}\geq 99.0 \\
\geq 99.9\end{array}$ \\
\hline $\begin{array}{l}\text { Decontamination factor (DF) } \\
{ }^{\mathrm{CH}_{3}{ }^{131} \mathrm{I}} \mathrm{I} \\
{ }^{2} \mathrm{I}_{2}\end{array}$ & $\begin{array}{l}\geq 10^{3} \\
\geq 10^{3}\end{array}$ \\
\hline
\end{tabular}

Notes: P-s the amount of the sorbent per $1 \mathrm{~cm}^{3}$ (“dry density"). ${ }^{*}$ Sorptive efficiency was determined under follow conditions: $\mathrm{T}_{\text {steam-air flow }}=35^{\circ} \mathrm{C} \div$ $280^{\circ} \mathrm{C}$; $v_{\text {gas flow }}=2 \div 60 \mathrm{~cm} / \mathrm{s}$; steam content in gas flow- $3 \div 80$ vol. $\% ; \tau$ ("gas flow-sorbent") $=0.3 \div 6.0 \mathrm{~s} ; \mathrm{T}_{\text {sorbent }}=35^{\circ} \mathrm{C} \div 280^{\circ} \mathrm{C} ; \mathrm{m}_{\text {sorbent }}=50 \div 100$ g; $\mathrm{h}_{\text {column }}=20 \div 50 \mathrm{~cm} ; \mathrm{S}_{\text {column }}=4.5 \div 7.0 \mathrm{~cm}^{2} ; \mathrm{m}\left(\mathrm{CH}_{3} \mathrm{I}\right)=5 \div 200 \mathrm{mg} ; \mathrm{m}\left(\mathrm{I}_{2}\right)=5 \div 200 \mathrm{mg}$. 
Table 2. Technical parameters of effective work of the sorbents "Fizkhimin”"TM

\begin{tabular}{lc}
\hline \multicolumn{1}{c}{ Parameter } & Value \\
\hline Temperature of the filtered medium, ${ }^{\circ} \mathrm{C}$ & $35 \div 145$ \\
Relative humidity of a filtered steam-air stream, $\%$ & $1.5 \div 95$ \\
Linear speed of a stream of the filtered medium, cm/s & $1.6 \div 16.3$ \\
Concentration of volatile radioactive iodine compounds, $\mathrm{g} / \mathrm{m}^{3}$ & $0.0003 \div 2.8$ \\
Quantity of radioactive iodine compounds on $1 \mathrm{~m}^{2}$ of filter cross- section, g & $0.11 \div 400$ \\
Temperature of effective sorbent work, ${ }^{\circ} \mathrm{C}$ & $30 \div 300$ \\
$\begin{array}{l}\text { Temperature of the radioactive iodine desorption beginning, }{ }^{\circ} \mathrm{C} \\
\text { Pressure difference on the } 250 \text {-mm layer of the sorbent at temperature } 20{ }^{\circ} \mathrm{C} \text { and linear speed of dry air flow }\end{array}$ & 600 \\
$1.6 \mathrm{~cm} / \mathrm{s}$, Pa & $6 \div 9$
\end{tabular}

Table 3. Sorption of the $\mathrm{CH}_{3}{ }^{131}$ I on the granulated sorbent "Fizkhmin",TM based on Ag nanometric compounds from a steamair mixture.

\begin{tabular}{ccccccccc}
\hline Type of sorbent & $\begin{array}{c}\text { The size of particles, } \\
\mathrm{mm}\end{array}$ & $\mathrm{h}, \mathrm{cm}$ & $\begin{array}{c}\mathrm{T}_{\text {sorb, }} \\
{ }^{\circ} \mathrm{C}\end{array}$ & $\begin{array}{c}\mathrm{T}_{\text {gas, }}{ }^{\circ} \\
\text { C }\end{array}$ & $\begin{array}{c}\mathrm{RH}, \\
\%\end{array}$ & $v, \mathrm{~cm} / \mathrm{s}$ & $\tau$, sec & $\begin{array}{c}\text { A degree of absorption on a } \\
\text { sorbent, \% }\end{array}$ \\
\hline IPCE-2 & $0.25-2.0$ & 5.0 & 145 & 145 & 57.3 & 22.0 & 0.4 & 99.9994 \\
-"- & $-"-$ & 20.0 & 145 & 145 & 21.0 & 61.0 & 0.3 & 99.9998 \\
IPCE-1 & $3.0-6.0$ & 45.0 & 35 & 35 & 95.0 & 5.0 & 8.8 & 99.8600 \\
$-"-$ & $-"-$ & 37.5 & 110 & 110 & 16.9 & 8.0 & 4.7 & 99.9995 \\
-"- & $-"-$ & 22.5 & 180 & 180 & 16.3 & 9.0 & 2.4 & 99.9995 \\
\hline
\end{tabular}

Notes: h-height of a layer of a sorbent in a column (the area of a column of $4.9 \mathrm{~cm}^{2}$ ), $\mathrm{T}_{\text {sorb }}$-temperature of a sorbent; $\mathrm{T}_{\text {gas }}$-temperature of a steam-air stream; $v$-linear speed of a steam-air stream in a column; $\tau$-time of contact “a sorbent-a steam-air flow" (for all layer of a sorbent); RH-relative humidity of a steam-air stream.

\section{Conclusion}

In conclusion, it is necessary to note, that the granulated sorbents "Fizkhmin"TM have very high sorptive efficiency in a wide range of experimental parameters. Therefore, they can efficiently be used for localization of volatile radioactive iodine compounds not only in passive filtering system, but also in other filtering devices, for example in the filters of emergency pressure release from containment operational NPPs during severe accidents.

\section{Announcement}

Work is supported by Council about grants of the President of the Russian Federation for the state support of leading scientific schools of the Russian Federation (grant SS-5418.2014.3).

\section{References}

[1] (2002) Reactor Design. Nucl. Engin., Advert. Supplement.

[2] Krebs, W.-D. (1999) The New Generation. Siemens Power J., 4, 10-13.

[3] (2003) Tomorrow's Reactors. Alternatives, 2, 4-5.

[4] Mikheev, N.B., Kulyukhin, S.A., Falkovskii, L.N. and Reshetov, L.A. (2002) Passive Filtration System of Intercontainment Shell. Heavy Engineering, 1, 45.

[5] Kulyukhin, S.A., Mikheev, N.B., Falkovskii, L.N., Zvetkova, M.Ya., et al. (2009) New Approach for Environmental Protection during Severe Accidents at Nuclear Power Plants. Proceedings of 17th Intern. Conf. on Nuclear Engineering, Brussels, Belgium. CD-ROM.

[6] Kulyukhin, S.A., Mikheev, N.B., Falkovskii, L.N., Zvetkova, M.Ya., et al. (2009) New Approaches for Decreasing of Environmental Emergency Contamination during Severe Accidents at Nuclear Power Plants. Proceedings of Intern. Conf. “Jahrestagung Kerntechnik’09”, Dresden, Germany. CD-ROM.

[7] Mikheev, N.B., Kamenskaya, A.N., Kulyukhin, S.A., Konovalova, N.A., et al. (2007/2009) Sorbent Based on Silica 
Gel for Localization of Volatile Forms of Radioactive Iodine. Russian patent 2346346. Register: 10.02.2009. Priority: 26.02.2007.

[8] Kulyukhin, S.A., Mizina, L.V., Konovalova, N.A. and Rumer, I.A. (2007/2009) Sorbent Based on Silica Gel for Localization of Volatile Forms of Radioactive Iodine. Russian patent 2346347. Register: 10.02.2009. Priority: 22.05.2007. 